\title{
LA PERSONA HUMANA EN LA VISIÓN ANTROPOLÓGICA DE KAROL WOJTYLA
}

\author{
The Human Person in the Anthropological Vision of Karol Woityla
}

\author{
Analyda Boluarte Drago* \\ Recepción: 14-01-2018 \\ Aceptación: 25-05-2018
}

\begin{abstract}
RESUMEN
No es un dato irrelevante, el estar delante de un poeta y dramaturgo, filósofo, teólogo, sacerdote y más adelante Pontífice; pues la riqueza de su producción intelectual legada al mundo contemporáneo, es de vanguardia y tiene plena vigencia.

Como eje conductor, se consideran dos textos del autor: Amor y responsabilidad (1960) y Persona y acción (1969). Se tendrá en cuenta como referencia a uno de los estudiosos de su pensamiento: Dr. Juan Manuel Burgos Velasco, fundador y presidente de la Asociación Española de Personalismo y de la Asociación Iberoamericana de Personalismo.
\end{abstract}

\section{PALABRAS CLAVE}

Persona, cuerpo humano, Karol Wojtyla, acción, manifestación, autodeterminación

\begin{abstract}
It is not an irrelevant fact to be in front of a poet and dramatist, a philosopher, theologian, priest and later Pontiff, for the wealth of his intellectual production, bequeathed to the contemporary world, is avant-garde and fully relevant today.

As a guiding principle, two texts by the author are considered: Love and Responsibility (1960) and Person and Action (1969). Also, as a reference, it will be taken into account the work of Dr. Juan Manuel Burgos Velasco, founder and president of the Spanish Association of Personalism and the Ibero-American Association of Personalism.
\end{abstract}

\section{Keywords:}

Person, human body, Karol Wojtyla, action, manifestation, self-determination

* Directora del centro de orientación del Colegio Salcantay: aboluarte@salcantay.edu.pe 
Karol Wojtyla es uno de los grandes filósofos personalistas del siglo XX. Formado en el tomismo, tomó contacto con la fenomenología, a través de Max Scheler. Su gran intuición es que el pensamiento antropológico contemporáneo, sólo puede avanzar y superar los retos a los que se enfrenta a través de una síntesis entre tomismo y fenomenología, estructurada en torno al concepto de persona.

Se abre un inmenso panorama de temas a investigar, en torno a los aportes filosóficos de Karol Wojtyla, que serán siempre un motivo de reconocimiento a su incesante labor intelectual

Damos inicio a nuestras reflexiones, considerando las nociones que fueron la base de la visión intelectual acerca de la persona humana, sobre la cual -Karol Wojtyla- desplegará sus propias visiones antropológicas, que intentará interpelar al hombre moderno.

Dentro de la visión aristotélica tradicional encontramos la definición de la especie (hombre) a través del género más próximo (ser viviente) y el elemento que distingue una especie dada dentro de su género (dotado de razón). Esta definición es expresada de la siguiente manera: anthropos zoon noetikón, homo est animal rationale. "Esta definición contiene -al menos como evidencia primordial- la convicción de la reducción del hombre al mundo. La razón de esta reducción era, y sigue siendo, la necesidad de comprender al hombre. Este tipo de comprensión podría ser definida como cosmológica". (Wojtyla, 1998a, pp. 27-28)

La utilidad de la definición aristotélica, queda en evidencia, si tenemos en cuenta que atribuye su propia validez en el contexto de la antropología metafísica y presidirá el nacimiento de muchas ciencias particulares sobre el hombre concebido, precisamente, como "animal" con la característica de la racionalidad que lo distingue del resto de los vivientes. Esta facultad que posee el hombre, no puede constatarse en ningún otro ser visible, puesto que en ninguno encontramos manifestaciones de un pensamiento conceptual.

Por otro lado, al remitirnos a la conocida definición de Boecio, según la cual la persona es individua substantia rationalis naturae, es decir individuo de naturaleza racional, estaríamos resaltando la individualidad en cuanto ser sustancial que posee una naturaleza racional o espiritual: "...la definición de Boecio define sobre todo el "terreno metafísico", o la dimensión del ser en el que se realiza la subjetividad personal del hombre, afirmando la condición para "el cultivo" de este terreno sobre la base de la experiencia". (Wojtyla, 1998a, pp.29-30)

Wojtyla resaltará dentro de su visión personalista, que la experiencia del hombre no puede agotarse en la vía de la reducción "cosmológica", puesto que lo imprescindible es detenernos en lo que es irreductible, en lo que en todo hombre es único y no repetible, aquello por lo que cada hombre es no sólo "hombreindividuo" de un género o persona-sujeto. De esta manera, la imagen del hombre sería no sólo la correcta, sino completa. "Irreductible significa también todo lo que en el hombre es invisible, que es totalmente interior y por lo que todo hombre es como el testimonio evidente de sí mismo, de la propia humanidad y de la propia persona". (Wojtyla, 1998a, p.34)

Siguiendo el trayecto de su pensamiento llegará a afirmar, que la persona se distingue de los animales -aún de los más perfectos- por su interioridad, en la que se concentra una vida que le 
es propia, su vida interior. No se puede afirmar lo mismo de los animales, aunque sus organismos pasen por procesos psicofisiológicos parecidos o posean una constitución aproximada a la de los hombres.

La estructura de la persona comprende su interioridad, en la que descubrimos elementos de vida espiritual, lo cual nos obliga a reconocer la naturaleza espiritual del alma humana y de la perfección propia de la persona. Su valor depende de esta perfección. Por ser la persona no sólo cuerpo sino también espíritu encarnado, y residir en ello su perfección, no puede considerársela igual a una cosa. Por otra parte, un abismo infranqueable separa la psique animal de la espiritualidad del hombre. (Wojtyla, 2009, p. 150)

Dentro de sus planteamientos antropológicos, Wojtyla revelará su perspectiva fenomenológica, ontológica y personalista, al "... abandonar la visión dual del hombre -entendido como cuerpo y alma- para adoptar una visión tripartita que entiende al hombre como una composición de tres niveles, cuerpo, psique y espíritu, que en Wojtyla se corresponden con el nivel somáticovegetativo, psicoemotivo y la estructura de autodeterminación". (Burgos, 2014, p. 66)

En consecuencia, la antropología de Wojtyla destaca por utilizar términos que hacen referencia a lo propio de la persona humana, distinción que queda en evidencia en las siguientes palabras:

...Karol Wojtyla sostiene que la metafísica aristotélica de la naturaleza humana corre el peligro de "reducir el hombre al mundo", de no hacer justicia a lo propium del hombre, a aquello que lo distingue como persona. Wojtyla dice que hay un enfoque cosmológico en la tradición aristotélica que requiere ser completado con una visión más personalista, que estudie al ser humano no sólo en términos de sustancia, potencialidad, racionalidad, etc., sino también en términos de subjetividad, esto es, en términos tales como autopresencia, mundo interior, autodonación". (Crosby, 2007, p. 112)

A continuación, vemos conveniente citar palabras del autor en estudio, para comprender su visión intelectual: "Cualquiera que busca la verdad última sobre el hombre en sentido filosófico se mueve ahora no ya sobre un "terreno meramente metafísico", sino que encuentra elementos abundantes que atestiguan tanto la corporeidad como la espiritualidad del hombre y tanto mejor ponen de manifiesto la una y la otra". (Wojtyla, 1998a, pp.38-39)

Habiendo llegado a este punto, es preciso señalar que la persona humana es capaz de apartarse de lo exterior y reconocer su mundo interior, estando en condiciones de tomar consciencia de lo que experimenta, frente a situaciones vividas al igual que otras personas más, en simultáneo. Esta capacidad le permite pertenecer al mundo "exterior", formar parte de él -de una manera muy particular - y ser aval del mundo interior que únicamente él o ella pueden experimentar.

La comunicación de la persona con el mundo objetivo, con la realidad, no es solamente física, como se da 
en todo ser natural, ni únicamente sensitiva, como en los animales. En cuanto sujeto netamente definido, la persona humana se comunica con los otros seres por intermedio de su interioridad, mientras que el contacto físico que le es igualmente propio (puesto que posee un cuerpo y, en cierta medida, "es cuerpo"), y el sensitivo, a la manera de los animales, no son sus medios propios de comunicación con el mundo". (Wojtyla, 2009, p.30)

La antropología que propone Wojtyla se puede considerar dentro de un personalismo integral por dos motivos. En primer lugar, porque el análisis fenomenológico que realiza, lo fundamenta en la verdad profunda de la persona. Asimismo, es integral, al partir de la experiencia -interior y exterior, objetiva y subjetiva- de la persona, abarcando todas sus dimensiones humanas. De este modo, va perfilando su objetivo primario: elaborar una antropología que incorpore la subjetividad. Su propuesta será original al reconocer la experiencia del hombre como la más rica de las experiencias que él mismo puede tener, y a su vez, la más compleja. Con estos planteamientos le recuerda al hombre, que el acceso directo y efectivo a la realidad es: él mismo.

Para ello, toma como principio de la filosofía un concepto que incluya al mismo tiempo la objetividad y la subjetividad. Este concepto es el de la "experiencia". "Para él, la experiencia, es decir, la dimensión cognoscitiva de la vivencia a través de la cual interactuamos con el mundo, se compone de dos elementos indisolublemente unidos: la vivencia de un contenido (objetividad), puesto que siempre experimento algo concreto; y la vivencia de mí mismo al vivir o experimentar ese contenido (subjetividad)". (Wojtyla, 2014, en Prólogo, p. 17)

Dentro de la "experiencia", la subjetividad nos aporta una posibilidad más de destacar en cada ser humano su índole personal. Lo cual le llevará a decir a un estudioso de su pensamiento personalista, que Wojtyla: "... cree que el hecho histórico del recurso a la subjetividad de los últimos siglos ha capacitado a muchos pensadores para lograr una visión más adecuada del hombre como persona, y que eso puede lograrse, aunque no siempre haya sido así de hecho, sin la menor concesión al subjetivismo. Yo estoy enteramente de acuerdo con Wojtyla...". (Crosby, 2007, p. 112)

Al acentuar la importancia de la "experiencia", Wojtyla considera la necesidad de recurrir a la fenomenología - no en todo el despliegue filosófico, propio de esta corriente de pensamientocomo procedimiento metodológico. Saliendo al paso de una subjetividad que pudiera decantar en un idealismo o en un subjetivismo, resalta que su planteamiento hace referencia a una "subjetividadconciencia", que no se desarticula del "ser".

Habiendo resaltado la importancia de la doble vertiente de la experiencia que permite el acceso a la subjetividad de la persona, Wojtyla advierte que no se está limitando a considerar la consciencia de la acción humana, sino que pretende ir en la línea de los filósofos modernos y, dentro de esta perspectiva, la consciencia es la vivencia de sí como sujeto. En su esquema antropológico, integra la conciencia moderna, quitándole la posibilidad idealista de transformarse en "conciencia autofundante".

De este modo, irá incorporando en sus planteamientos antropológicos 
dos conceptos: "autoconciencia" y "autoconocimiento", creando el espacio necesario para la subjetividad y el "yo". Una vez que están definidos estos dos conceptos, inicia el análisis de la acción humana, desde la acción misma; siendo ésta la que -según sus planteamientos filosóficos- nos llevará a la persona. Esta reflexión en torno a la persona, puede realizarse, porque ya cuenta con el espacio antropológico (la subjetividad) lo que permite entender al sujeto de esa acción como un yo autoconsciente, cosa que, sin la integración previa de la consciencia, no habría sido posible. Nos habríamos encontrado con una acción vacía, sin sujeto.

Dentro del esquema filosófico que va elaborando Wojtyla acerca de los distintivos particulares de la persona humana, se encuentra el concepto de libre albedrío o "facultad de autodeterminación", que se manifiesta en el hecho de que, al actuar, el hombre elige lo que quiere hacer. Esta es una realidad propia de la persona humana, que le permite definir su existencia en la medida que la ejercita guiada por la recta razón: "Así pues, la naturaleza de la persona tiene una condición especial que marca una diferencia radical: que es libre". (Burgos, 2011 , p.110). El comentario a esta noción introducida por Wojtyla, nos permite un esclarecimiento adicional, para valorar el peso específico que le concede al concepto de "autodeterminación". "La trascendencia nos ha mostrado el nivel configurador de la persona, la autodeterminación; pero ésta no es solo autodeterminación, es también cuerpo y psique, tres estratos que se presentan en la experiencia de la acción de forma sólidamente unitaria. Es el hombre, la persona humana quien actúa; no ninguno de esos estratos de modo independiente". (Burgos, 2014, p. 69).
Es importante señalar que libertad, dentro de la reflexión filosófica de Wojtyla, no es tan sólo una cualidad de la acción, sino una cualidad del ser persona. La libertad como autodeterminación, no sólo describe un rasgo específico del hombre, sino que ésta define a la persona, puesto que dispone de la estructura de autodeterminación y ser persona -para élson conceptos equivalentes. La capacidad dinámica que posee el hombre, le permite separarse de su acción, distinguirse de ella, analizarla y es lo que denominará: "trascendencia". "Esta trascendencia tiende dos dimensiones: la horizontal, que se identifica con la elección, que la filosofía tradicional ha tratado con precisión; y la autorreferencial o vertical, que consiste en la autodeterminación". (Burgos, 2014, p. 66)

Con la finalidad de ampliar un poco más la "trascendencia" dentro de los postulados filosóficos de Wojtyla nos remitimos a una cita -algo extensa- pero muy esclarecedora:

La transcendencia vertical, que es la clave de bóveda de todo el pensamiento de Wojtyla, sobrepasa la subjetividad hacia el interior más que hacia el exterior, y se dirige hacia el núcleo irreductible del hombre que parece transcendente incluso en el sentido metafísico. En la acción, el hombre muestra que es alguien por su capacidad de dominio y de posesión de sí, que le permite tener la experiencia de sí mismo como un ser libre. Esta experiencia de la libertad nos lleva a admitir la causalidad eficiente del hombre hacia la acción y, por tanto, su responsabilidad en ella. La libertad, además, reposa en la relación de la persona con la verdad, que le permite no estar 
determinado de una manera unilateral por las circunstancias. La relación de la libertad con la verdad es, en fin, el factor decisivo de la transcendencia de la persona en su acción. Todo este proceso de pensamiento no es desarrollado por Wojtyla más que por medio del método fenomenológico. Parece, pues, que el empleo de este método pueda llevarnos a reconocer que el hombre es esencialmente espíritu. (Buttiglione, 1992, p. 183)

Siguiendo en la línea antropológica de Wojtyla, encontramos que la palabra "espíritu" hace referencia a la transcendencia de la persona con la experiencia de la libertad, de la responsabilidad y de la lealtad hacia la verdad y el bien: "Por consiguiente, hemos descubierto el espíritu como realmente inmanente al ente que es el hombre. La transcendencia fenomenológica de la persona en el acto nos conduce al umbral de la transcendencia de la persona entendida en sentido metafísico". (Buttiglione, 1992, p. 183)

El concepto de persona humana que nos plantea Wojtyla integra los conceptos tomistas, destacando el dinamismo propio del hombre, ya que, al poseer una estructura de autodeterminación, es distinguido por ser "un quien" capaz de auto-determinarse a través del análisis de sus acciones. Es más, se puede afirmar siguiendo la reflexión wojtyliana- que esta estructura se hace efectiva en la acción. "Esto permite entender un poco más su afirmación de que "la acción revela a la persona". La revela o desvela en el sentido de que es proceso de autodeterminación que sólo se da en la acción. El que nos muestra quién es el sujeto-persona". (Wojtyla, 2014, en el Prólogo p. 22)
Una vez definida la autodeterminación dentro de la antropología ontológica wojtyliana, estamos en condiciones de ahondar en sus reflexiones. Como parte estructural de la persona, Wojtyla resalta dos características adicionales que se desprenden de la autodeterminación. Éstas se activan, en la medida que la persona decide acerca de sí mismo -aunque de manera limitada, ya que la libertad humana no es absoluta-, y concibe dos características propias: el autodominio y la autoposesión: "... la persona puede transcender, por las estructuras del dominio y de la posesión de sí, los dinamismos que se manifiestan espontáneamente en el hombre. No es posible comprender esta totalidad dinámica que son la persona y su acción si uno no se sitúa en el punto de vista de la transcendencia de la persona". (Buttiglione, 1992, p. 186).

Wojtyla seguirá profundizando en el cometido de definir a la persona humana y en algún momento enlazará nuevamente con postulados tomistas al explicar que la capacidad de autodeterminación -si bien, es estructural- únicamente permitirá alcanzar la plenitud de la persona, si en su ejercicio se orienta en sentido positivo hacia el bien y la verdad. A esta disposición de la autodeterminación la denominará "autorrealización".

Para alcanzar esta autorrealización, es necesario que la persona se detenga en lo que su inteligencia le muestra como verdadero y bueno. Se va haciendo evidente, la preocupación de Wojtyla por la acción humana -la ética - al relacionarla con la verdad y el bien. En base al manejo de conceptos tales como subjetividad, autoconocimiento y consciencia, la persona -con toda esta estructurano necesita buscar en el exterior los referentes, ya que la autorrealización, 
que no es una simple tendencia- permite captar el valor de la verdad y ante ella, dar una respuesta activa.

Esta respuesta activa será la que revela el interior del hombre y se manifiesta de manera conjunta, con una noción propia de la trascendencia de la persona, sobre su acción: "la responsabilidad". "Libertad y responsabilidad no solo están intrínsecamente entrelazadas, sino que son las dos caras de una misma moneda. La acción es la respuesta causada libremente por el sujeto ante determinadas circunstancias y, lo desee o no, no puede más que ser responsable ante ella, puesto que es él quien la ha puesto en la existencia". (Burgos, 2014, p. 68).

Siguiendo los conceptos que acuña en su antropología ontológica, encontramos una definición de la estructura de la persona, por lo que podríamos afirmar que Wojtyla habría logrado su objetivo: construir una nueva visión de la persona partiendo del análisis de la experiencia.

\section{REFERENCIAS}

\section{PRIMARIAS}

Wojtyla, K. (2014). Persona y acción. Madrid: Ediciones Palabra.

Wojtyla, K. (2009). Amor y responsabilidad. Madrid: Ediciones Palabra.

Burgos, JM. (2014). Para comprender a Karol. Madrid: Biblioteca de Autores Católicos.

Burgos, JM. (Ed) (2007a). La filosofía personalista de Karol Wojtyla. Madrid: Ediciones Palabra.
Buttiglione, R. (1992). El pensamiento de Karol Wojtyla. Madrid: Ediciones Encuentro.

Guerra, R. (2002). Volver a la persona. El método filosófico de Karol Wojtyla. Madrid: Editorial Caparrós.

\section{SECUNDARIAS}

Burgos, JM. (2003a). Antropología: una guía para la existencia. Madrid: Ediciones Palabra

Burgos, JM. (.2003b). El personalismo. Madrid: Ediciones Palabra.

Burgos, JM. (2007b). Repensar la naturaleza humana. Madrid: Ediciones Internacionales Universitarias, S.A.

Burgos, Juan Manuel (2009). Reconstruir a la persona. Madrid: Ediciones Palabra.

Burgos, JM. (Ed) (2011). El giro personalista del: qué al quién. Madrid: Fondo Editorial Emmanuel Mounier

Crosby, J. (2007). La interioridad de la Persona Humana. Hacia una antropología personalista. Madrid: Ediciones Encuentro.

Juan Pablo II. (1994). Cruzando el umbral de la esperanza. Colombia: Editorial Norma.

Juan Pablo II. (1995). Carta a las Mujeres. Madrid: Ediciones Palabra.

Juan Pablo II. (1996). Don y misterio. Madrid: Editorial Biblioteca de Autores Cristianos. 
Juan Pablo II (1998). Carta Apostólica Mulieris dignitatem. Lima: Editorial Salesiana

Juan Pablo II. (2004). iLevantaos! iVamos! Buenos Aires: Editorial Sudamericana.

Juan Pablo II. (2005). Memoria e identidad. Madrid: Editorial La Esfera de los libros.
Juan Pablo II. (2010). Hombre y mujer los creó. Catequesis sobre el amor humano. Madrid: Ediciones Cristiandad. 